\title{
FRONTEIRAS LINGUÍSTICAS E FRONTEIRAS POLÍTICAS: RELAÇÕES LINGUÍSTICAS E SOCIO- HISTÓRICAS NA FRONTEIRA DO BRASIL COM A GUIANA FRANCESA
}

Kelly Cristina Nascimento Day

\section{RESUMO}

Este artigo destaca a realidade da fronteira franco-brasileira, permeada por seus aspectos históricos e sociais, e o estudo do contato. Partindo do conceito de contato e dos fenômenos que dele advêm, elaboramos um quadro histórico, sociocultural e linguístico da fronteira do Brasil com a Guiana Francesa e dos resultados desse contato na vida cotidiana dos habitantes. Para concluir, discutimos questóes relativas às políticas linguísticas educativas em voga na regiáo.

PALAVRAS-CHAVE: Fronteiras políticas; contato linguístico; usos sociais.

\section{Considerações iniciais}

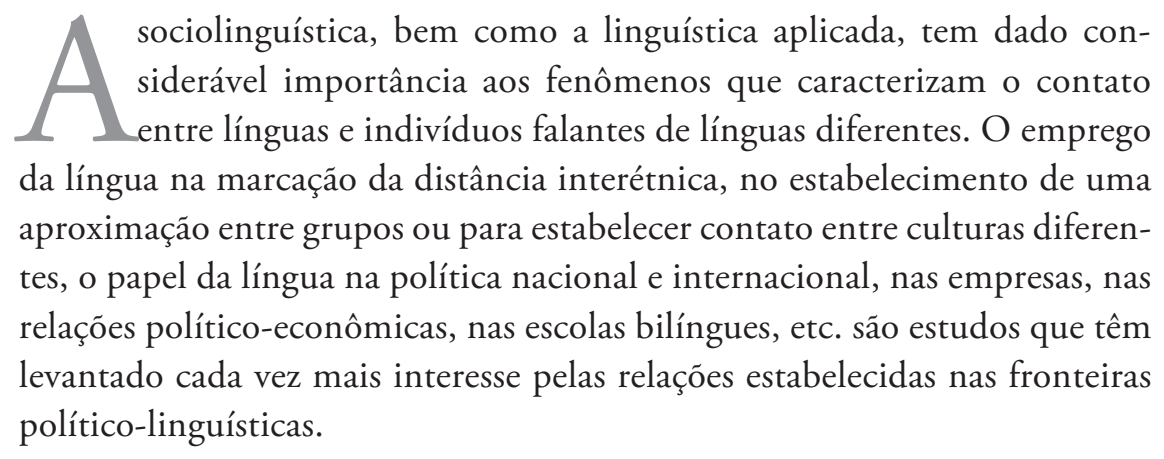


Embora fronteiras linguísticas e fronteiras políticas raramente sejam coincidentes, elas comumente resultam em processos diversos e complexos de mesclagem ou de divergência social, cultural e linguística, cujas dinâmicas se repetem em diferentes comunidades.

No Brasil há onze unidades federadas que dividem zonas fronteiriças com diferentes países, abrangendo cerca de 580 municípios. Embora estas localidades sejam caracterizadamente contextos linguístico-sociais peculiares, eles ainda são desconhecidos, em sua maioria, tanto do ponto de vista linguístico quanto sociocultural.

Neste trabalho, fundamentado em uma pesquisa inédita realizada objetivando traçar um perfil sociolinguístico das comunidades de Oiapoque e Saint Georges na fronteira do Brasil com a Guiana Francesa (Day, 2005) ${ }^{1}$, apresentamos um quadro histórico geral da fronteira, bem como alguns reflexos sociais e linguísticos do contato.

\section{I - Fronteiras políticas e fronteiras linguísticas}

A fronteira política é uma noção ao mesmo tempo dicotômica e arbitrária. Dicotômica porque a linha que separa um país de outro parece determinar ficticiamente "o que se faz e o que não se faz", "o que é e o que não é", "o que se diz e o que não se diz" dentro de um limite espacial; e arbitrária porque normalmente é delimitada de modo artificial e o traçado geopolítico não é motivado por considerações culturais que mantenham estreita relação com a língua (Viaut, 2004, p.6) ${ }^{2}$.

Por outro lado, não se pode esquecer que, além do seu caráter de reivindicação territorial, a fronteira política também se reveste de outro significado, qual seja, o de lugar privilegiado onde se efetuam as confrontaçóes interculturais, interétnicas e interlinguísticas. Zonas de particular fecundidade como é o caso da Catalunha, da Normandia, da Borgonha, e inúmeras outras, áreas comumente assimiladas como zonas intermediárias ou de passagem, é comum

1 DAY, Kelly. A Situação Sociolinguística da Fronteira Franco-Brasileira: Oiapoque \&Saint Georges. Rio de Janeiro, RJ, 2005. 106 p. Dissertaçáo (mestrado em Estudos da Linguagem). Pontifícia Universidade Católica do Rio de janeiro, PUC - Rio.

2 VIAUT, A. "La Frontière linguistique de la ligne à l'espace : éléments pour une schématisation «. Glottopol, Revue de Sociolinguistique en Ligne, 4: 6-20, Rouen, 2004. 
que ocorram fenômenos ligados às línguas ali utilizadas, tais como difusão, intercâmbios, hibridização, bilinguismo, etc.

Isto posto, é pertinente dizer que um dos parâmetros paradoxais que delimitam a fronteira política do Estado-nação é exatamente a língua, que contribui tanto para determinar a fronteira quanto é influenciada por sua presença, muitas vezes transcendendo-a. Ela, a fronteira, constrói e modifica a língua e por ela é construída e modificada. Sendo linha separadora, a fronteira política assinala um distanciamento espacial ao mesmo tempo em que se estabelece enquanto linha de contato e intercâmbio.

A fronteira linguística, por outro lado, bem como o território que ela circunscreve, certamente não é um simples resultado ou um simples dado, mas uma produção determinada por uma socialização e um posicionamento de parte dos diferentes atores sociais nela envolvidos. Na geografia social, é a quantidade e a natureza das adesóes individuais e sociais a uma mesma representação do espaço que acaba por construir um território e uma prática de territorialidade (Di Méo, 1998, p.55-56) ${ }^{3}$. O mesmo acontece com a fronteira linguística que decorre da delimitação conscientizada de um espaço linguístico, sendo ele a constatação de uma realidade estabelecida ou que tende a ser criada.

De um ponto de vista macro sociolinguístico, a expressão fronteira linguística é empregada no presente trabalho para designar o limite externo de uma língua tal qual ele se desenha em virtude das distâncias linguísticas significativas com conjuntos vizinhos ou como resultado de processos voluntaristas de individualização (Marcellesi \& Gardin, 1974, p. 162) ${ }^{4}$ ou, ainda, como resultado de usos reais, ligados à formalização legal e administrativa.

Alain Viaut (op. cit.) compreende a fronteira linguística como uma macro-noção que se subdivide em duas sub-noçóes baseadas em critérios de disposição no espaço, dos delineamentos que alimentam a ideia de fronteira linguística em sentido amplo: a "exofronteira" e a "endofronteira linguística”.

3 DI MEO, G. «Le Territoire: un concept essenciel de la géographie sociale «. Les documents de la maison de la Recherche en Sciences Humaines de Caen, no 7 (colloque de Géographie sociale de Caen, Octobre, 1996), 1998.

4 MARCELLESI, J-B et GARDIN, B. Introduction à la sociolinguistique : la linguistique sociale. Paris: Larousse, 1974, 263 p. 
A "exofronteira” compreende o limite linguístico tradicional externo, a língua herdada, transmitida in loco ou em relação com o território linguístico de origem, passando de geração para geração, bem como os limites instituídos tendo por principal origem os fatos ou a realidade de ordem político-administrativa, a começar pela fronteira política.

No âmbito da "exofronteira" linguística está inserida tanto a questão da oficialidade da língua, uma vez que os limites administrativos ou os atos políticos podem fortalecer ou fragmentar uma entidade linguística, quanto aquela do limite linguístico-identitário, produto do imaginário, do mito e, mais globalmente, das representaçóes que também são importantes para aproximar o limite sociolinguístico dentro de uma lógica de fronteira, de construção identitária, regional ou nacional. A língua, enquanto marcador identitário, também constitui um elemento delimitador de território.

A "endofronteira" linguística, por sua vez, concerne aos fatos internos. Ela é mais um retrato da compartimentalização interna das línguas, dos limites determinados pela variação de uso, de acordo com as épocas, pela tradição, em dialetos e falares regionais. Os limites internos testemunham a diversidade dos usos no interior das áreas da língua, tanto determinados por critérios sociodemográficos e econômicos quanto por outros que resultariam de medidas de planificação linguística.

A inadequação entre estes dois tipos de fronteira pode assim vir acompanhada de tratamentos diferenciados. Essa inadequação, que resultaria mais "do acaso da história que das relações de comunicação tradicionais", estaria também na origem de "influências recíprocas cujos falantes com o tempo acabam por interiorizar os efeitos" Viaut (op.cit., p. 15). Desse modo, a fronteira estática agiria sobre o corpus da língua, na fixação de traços linguísticos distintos nos dois territórios que são, por sua vez, administrados cada um de modo homogêneo.

Em virtude da porosidade das fronteiras linguísticas, as palavras, bem como as pessoas e as coisas, vão e vem, tanto em função dos intercâmbios fronteiriços e sub-regionais quanto pela diferença entre as fronteiras nacionais e os limites étnicos, culturais ou linguísticos, dando origem a fenômenos diversos provenientes do contato e abrindo o campo para estudos sobre o bilinguísmo e sobre a influência que uma língua pode exercer sobre a outra, sobretudo na área de empréstimos e da interferência linguística. 
As regiōes fronteiriças entre nações não raro são marcadas por um alto grau de bilinguismo. Mas ser sujeito bilíngue nestas regióes é, muitas vezes, condição necessária para a construção de indivíduos polissociais (Mackey, 1976, p.19) $)^{5}$ que tanto podem fazer parte de um grupo social específico quanto de outro, em contextos diferenciados.

As comunidades linguísticas de fronteira, e por comunidade linguística compreendemos "um conjunto de pessoas que interagem verbalmente e que compartilham um conjunto de normas com relação aos usos linguísticos" (Alkmin, 2000, p. 31) ${ }^{6}$, são colocadas frente a frente interagindo por meio de redes comunicativas diversas, com regras de comportamento verbal por vezes divergentes. Nesse "confronto", guardada a indissociabilidade do binômio língua-cultura, colocam-se em contato, além das estruturas e regras linguísticas, fundamentalmente indivíduos que carregam consigo suas bagagens sociais, culturais, étnicas e suas representaçôes de mundo e do outro.

\section{II - O contato linguístico e as áreas de fronteira}

Uma vez que raramente uma língua se encontra isolada no espaço, toda comunidade linguística estabelece, cedo ou tarde, relaçóes mais ou menos estreitas com outros grupos, com outros falares. Tais relaçóes intergrupais, concretizadas pelo viés da língua, frequentemente são complexas e variam no espaço geográfico, social e através do tempo. Contato linguístico é o termo comumente empregado na literatura para designar essas relaçóes.

O contato entre os povos é resultante de uma realidade social e histórica que, caprichosamente e por motivos diversos, colocou frente a frente indivíduos falantes de línguas diferentes. Este intercâmbio sem precedentes que se configura nos dias atuais entre os povos, impulsionado pelos elementos da vida moderna como a mídia e a internet, o comércio internacional e o turismo, faz com que o cidadão de hoje deva ser, por definição, plurilíngue.

A história das línguas e das relaçóes humanas tem mostrado que todas as línguas têm sofrido influência uma das outras e os fenômenos linguísticos

5 MACKEY,W.F. Bilinguisme et Contact des Langues. Paris : Editions Klincksieck, 1976, 534 p.

6 ALKMIN, T. “Sociolinguística”. In: MUSSALIM, F. \& BENTES, A. (Org.). Introdução a Linguistica: Dominios e Fronteiras. São Paulo: Cortez Editora, 2004, p. 21-47. 
resultantes do contato entre pessoas que falam línguas diferentes em um mesmo território ou em espaço contíguo, como é o caso das fronteiras, são bastante variados.

Tais fenômenos diferem em função de diferentes fatores, dentre os quais estão a duração do contato, a intensidade da relação entre os povos e/ou comunidades linguísticas, os tipos de relaçôes sociais, econômicas e políticas estabelecidas entre eles, as funções de comunicação e o status das línguas em presença.

Em uma situação de línguas em contato, o status de cada língua varia de acordo com as relaçóes de força existentes entre os grupos que as utilizam, bem como em função da percepção que os indivíduos têm destas relaçôes. Para Mackey (op. cit., p. 211),

As línguas exercem um poder de força umas sobre as outras e as diferenças de poder se manifestam quando as línguas estão em contato. Elas se manifestam como uma forma de atração ou de repulsão que uma língua, ou melhor, aqueles que a utilizam, terão um pelo outro.

Os elementos que conformam o status de uma língua não são apenas jurídicos, mas estão colocados em termos de força e atração linguística. A importância de uma língua está muito mais relacionada com a função que ela exerce enquanto veículo que permite a comunicação com aqueles que são importantes nos diversos domínios relacionados (comércio, religião, educação, ciências, cultura, esportes, lazer) do que com seu valor linguístico interno.

Por outro lado, ela também possui em si mesma uma importância que provém dos povos que a utilizam, do número de pessoas, de suas riquezas, de sua mobilidade, de sua produção cultural e econômica, fatores cuja soma constitui o que nomeamos de poder inato de cada língua (Mackey, op.cit., p. 212).

Em outras palavras, podemos dizer que toda língua estabelece uma relação de poder com as línguas em que está em contato e esta relação dependerá do poder relativo de cada uma delas, das diferenças linguísticas existentes e da proximidade dos povos. Ocorre, entáo, em consequência, que os usos linguísticos e os resultados do contato podem variar em função do espaço social ou geográfico, ou de acordo com o grau de diferença e poder entre as línguas. A 
atração ou repulsão entre elas seria então, segundo Mackey (op.cit., p. 216), função de três distâncias: a distância de poder, a distância geográfica e a interlinguística.

A distância de poder está diretamente vinculada à relação de motivos que um indivíduo possui para aprender e para utilizar uma determinada língua. $\mathrm{O}$ inglês hoje tem status de língua internacional, importante em todos os setores do mercado econômico, da pesquisa científica e da tecnologia, o que o coloca em um patamar de poder diferenciado nas sociedades atuais.

A distância geográfica estabelece que a atração que pode exercer, efetivamente, uma língua sobre um povo falante de outra língua dependerá das possibilidades e das probabilidades de contato. Uma língua de alto poder, como o inglês, não terá nenhuma influência direta sobre um povo que tem pouca ou nenhuma possibilidade de ouvir ou de ler em inglês. Significa dizer que a força de atração do poder linguístico é atenuada pela distância e aumenta com a aproximação.

No passado, a atração da proximidade foi atenuada em certa medida pela presença de barreiras naturais - as montanhas, os rios, os lagos -, fatores que foram utilizados para justificar a divergência no interior de uma mesma família linguística, tais como as línguas latinas e as línguas germânicas. Atualmente, na era da internet, estas barreiras naturais não têm a mesma influência, mas a distância terrestre ainda é significativa.

A distância interlinguística está relacionada com as diferenças internas entre as línguas, que por sua vez não são nada negligenciáveis. A similaridade entre duas línguas constitui em si uma força de atração. Desta forma, os brasileiros estão de modo geral mais propensos ao espanhol que ao inglês ou ao alemão, enquanto que os alemães terão maior propensão para uma língua germânica. Assim como a distância geográfica, a interlinguística diminui a força de atração de uma língua para outra.

Destas relações resultam diferentes fenômenos de variações sociolinguísticas, que tanto podem culminar na efetivação de empréstimos, na utilização de duas ou mais variedades de uma mesma língua e/ou de línguas diferentes, quanto podem levar à formação de novos falares.

Destacamos nesse sentido, para não nos estendermos na temática já bastante explorada, que tanto o bilinguismo, compreendido aqui como uso regular, por um mesmo indivíduo, de duas línguas na vida cotidiana e não 
competência semelhante ou perfeita nas duas línguas, quanto o multilinguismo, que envolve o uso de mais de duas línguas por um dado grupo social, são fenômenos característicos do contato e são comumente registrados nas regiōes fronteiriças. É nesse âmbito que Hamers \& Blanc (1989, p. 12 - 27) ${ }^{7}$ propóem um novo par conceitual, o de bilinguismo e bilingualidade, o primeiro referindo-se ao fenômeno societal e o segundo ao individual.

Vale destacar ainda que o bilinguismo é um fenômeno de dimensóes múltiplas, cujo grau de variação depende do lugar onde se encontram os falantes, de suas origens, da proeminência das línguas e das funçóes que exercem as línguas no meio social, como ocorre no caso das fronteiras (ver Mackey, 1976 ${ }^{8}$; Hamers \& Blanc, 1983, op.cit.; Heye, 1979'; Savedra, 2003 ${ }^{10}$ ).

\section{III - As fronteiras político-linguísticas no Brasil e o estudo do contato}

Investigar as fronteiras linguísticas e os resultados inerentes ao contato nestas áreas não é uma longa tradição nos estudos linguísticos no Brasil. Até meados dos anos 1990, muito pouco havia na literatura sobre a realidade das fronteiras linguísticas brasileiras. Os poucos relatos existentes eram, em geral, secundários ou pouco fundamentados, com algumas exceçóes como fora o caso da fronteira Brasil/Uruguai ${ }^{11}$.

Nas duas últimas décadas, no entanto, diferentes abordagens (sociolinguísticas, ecolinguísticas, discursivas, linguístico-descritivas) das fronteiras brasileiras têm levantado questóes relevantes relacionadas a estas comunidades, dada, sobretudo, a realidade que se instala: a dos grandes mercados mundiais e regionais.

7 HAMERS, J.F \& BLANC, M. Bilingualité et bilinguisme. Bruxelles : Pierre Margada Editeur, 1983, $498 \mathrm{p}$.

8 MACKEY, W. F. Bilinguisme et Contact des langues. Paris : Editions Klincksieck, 1976. 540 p.

9 HEYE, J. "Sociolingüística”. In : PAIS, C. T. \& RECTOR, M. Manual de Lingüística. Petrópolis: Vozes, 1979. p. 203-239.

10 SAVEDRA, M. "Dimensões de bilingualidade em contextos educacionais bilíngües: fatores de impacto na política e planificação lingüística”. In: RONCARATI, C. \& ABRAÇADO, J. (Org.). Português Brasileiro. Rio de Janeiro: 7 Letras, 2003. p. 236-252.

11 Os primeiros trabalhos relevantes sobre as fronteiras brasileiras em uma perspectiva de contato são os trabalhos de Hensey (1972) e de Elizaincin, Behares e Barrios (1987). 
Os avanços no processo de integração regional, no qual se insere o Brasil, face, sobretudo, às necessidades de cooperação político-econômica e cultural no quadro do MERCOSUL, têm elevado a um novo patamar de discussão as questôes fronteiriças e entre elas a linguística.

É no enfoque desta temática que Otto (2002, p. 84) ${ }^{12}$ afirma:

As regióes fronteiriças ou limítrofes, nas quais vivem habitualmente minorias linguísticas e que antigamente vegetavam e faziam "Office de glacis" escapam cada vez mais a sua condição periférica para se inscrever nas relaçóes binacionais transfronteiriças... ou ainda são retiradas de sua letargia graças a medidas objetivas de desenvolvimento regional.

Refletindo sobre a intensidade das interaçóes entre os povos de áreas contíguas, o que vêm reforçando a concepção de fronteira enquanto espaço de comunicação e troca, Ganster et al. (1997, p. 376) ${ }^{13}$ compreende que as regiôes de fronteira constituem pontes entre naçóes, que ajudam a eliminar as barreiras físicas e psicológicas (e mesmo as linguísticas), tornando mais abrangentes as formas de cooperação internacional.

É neste quadro que estão contempladas as fronteiras de norte a sul do Brasil; com esta última muito mais em evidência devido a sua posição estratégica em relação aos países membros do Mercado Comum do Sul e a consequente proximidade com o espanhol, língua que, ao lado do português, caracteriza o MERCOSUL. As fronteiras do norte, ainda que silenciosamente, também vêm vivenciando um lento processo de valorização de suas condiçóes geopolíticas e linguísticas, porém muito mais em função de suas próprias necessidades de comunicação, de integração, de desenclave regional, político e econômico do que pela condição de parte do bloco econômico regional.

Testemunhando o crescente avanço destes estudos no país, diversos trabalhos no contexto do contato linguístico em áreas de fronteira foram

12 OTTO, C. «La situation glottopolitique de l'Alsace - aspects synchroniques». Sociolinguistica no16 (online), p. 84-93, 2002.

13 GANSTER et al. Border and Border Régions in Europe and North América. San Diego: IRSC/ SDSU press, 1997, $376 \mathrm{p}$. 
elaborados; dentre eles destacamos os trabalhos de Espiga (2006) ${ }^{14}$ sobre a fronteira Chui/Chuy, de Lupski (2011) ${ }^{15}$ sobre a fronteira Brasil/Bolívia, Couto $(2011)^{16}$ sobre a zona de fronteira Brasil/Uruguai, Braz $(2010)^{17}$ e Silva $(2012)^{18}$ sobre a fronteira Brasil/Venezuela, Barbosa (2009) ${ }^{19}$ sobre a fronteira Brasil/Colômbia e Ferreira \& Silva (2012) ${ }^{20}$ abordando o contato linguístico na fronteira Brasil/Bolívia.

Como é comum nestas áreas, a extensão e a intensidade dos contatos estão definidas pelas características geográficas, econômicas, sociais e culturais. $\mathrm{Na}$ maioria das zonas fronteiriças do Brasil, as comunidades estão separadas por acidentes geográficos, o que normalmente diminui a frequência e a extensão do impacto da língua do país vizinho em território brasileiro.

A fronteira seca, como são denominadas as áreas em que não há nenhuma barreira geográfica natural, como é o caso de Santana do Livramento no Brasil e Rivera, no Uruguai, apresenta, em geral, uma realidade linguística bastante marcada pelo longo processo de contato. A situação sociolinguística dessa fronteira (Hensey, 1972) 21 $^{1}$ é um dos trabalhos mais bem elaborados de que se tem notícia na literatura a respeito das áreas de fronteira no Brasil. $\mathrm{O}$ panorama linguístico da zona fronteiriça uruguaio-brasileira revelou o uso do dialeto denominado fronteiriço, resultado da mistura do português e do espa-

14 ESPIGA, J. "O contato do português com o espanhol no sul do Brasil". In: VANDRESSEN, P. (Org.). Variação, mudança e contato linguístico no português da região sul. Pelotas: Educat, 2006. P. 261-280.

15 LIPSKI, J. “Um caso de contato de fronteira”. In MELLO, H. et al.(Org.). Os contatos linguísticos no Brasil. Belo Horizonte: Editora UFMG, 2011, p. 349-368.

16 COUTO, H. "Contato entre português e espanhol na fronteira Brasil-Uruguai". In: MELLO, H. et al.(Org.). Os contatos linguísticos no Brasil. Belo Horizonte: Editora UFMG, 2011, p. 369-395.

17 BRAZ, E. Línguas e identidades em contexto de fronteira Brasil/Venezuela. Campinas, SP, 2010. Dissertação de mestrado. Instituto de Estudos da Linguagem. Unicamp.

18 SILVA, M. O Ethos em "la línea" de fronteira Brasil/Venezuela: ambiente ecolinguístico e redes sociais. Rio de Janeiro, 2012. Dissertação de mestrado. UFRJ.

19 BARBOSA,G. "Atitudes em fronteira: o caso de Tabatinga e Letícia". Cadernos do CNLF, vol.XI, nº15: 68 - 84, Rio de Janeiro: CIFEFIL, 2009.

20 FERREIRA, S; SILVA, R. "Contato linguístico na fronteira Brasil-Bolívia: Hibridaçóes étnicas, culturais e sociais”. Estudos Históricos - CDHRPyB - año IV, 2012, no 9. ISSN 16885317. Uruguay.

21 HENSEY, F.G. The Sociolinguistics of the Brazilian-Uruguayan Border, Paris: Mouton, 1972, $115 \mathrm{p}$. 
nhol, falado, sobretudo, nas comunidades rurais do interior do Uruguai, e que estão geograficamente localizadas na faixa de fronteira com o Brasil.

A fronteira geolinguística Brasil/Guiana Francesa, objeto central deste trabalho, a exemplo das áreas de fronteiras contíguas, tem características histórico-sociais bem particulares no contexto geral das fronteiras brasileiras. Dentre todos os trabalhos já realizados, a pesquisa de Day (op. cit.) configura-se como o primeiro que delimita o contato em zona fronteiriça do português com a língua francesa e crioulos de base francesa no Brasil.

A regiāo fronteiriça de Oiapoque, do lado brasileiro, e Saint Georges de l'Oyapock, do lado francês, comporta hoje um quadro sociolinguístico que merece ser acompanhado. Diferentes etnias ameríndias habitam a região, além da comunidade brasileira não indígena que tem como língua oficial o português e da comunidade franco-guianense, composta de franceses metropolitanos, guianenses e imigrantes de origens diversas. Junto com o português e o francês, as línguas oficiais, compóem o ambiente linguístico fronteiriço diferentes línguas indígenas e o crioulo de base francesa.

\section{IV - A fronteira político-linguística franco-brasileira: aspectos históricos e geográficos}

Diferente das regióes sul, oeste e parte do norte do Brasil, que se limitam com países de língua espanhola, no extremo norte o Amapá divide cerca de $600 \mathrm{~km}$ de fronteira com um departamento francês ultramarino, a Guiana Francesa, a única que o país guarda como uma região francófona.

A regiāo que se estende do rio Oiapoque ao rio Araguari, no Estado do Amapá, foi marcada por uma extensa história de contestado entre o Brasil e a França, ao longo da qual as situaçóes de contato linguístico entre os diversos povos e línguas da regiáo foram certamente uma constante.

Do século XVI ao século XVIII, cerca de metade do território que hoje compreende o Estado do Amapá foi espaço de disputa entre Portugal e França e, posteriormente, entre França e Brasil. Ao longo de dois séculos, a então capitania do Cabo Norte esteve dominada e explorada por comerciantes e exploradores provenientes da Guiana Francesa.

Somente por volta de 1750, Portugal começa a preocupar-se com a exploração e a defesa da regiáo que estava seriamente ameaçada pelos planos 
expansionistas da França na faixa equinocial da América. Com o estímulo da coroa portuguesa, imigrantes açorianos e marroquinos iniciam a ocupação do território, porém, nem a presença constante de missionários, mercadores e militares, e nem mesmo a construção do forte de São José de Macapá, erigido com o intuito de proteger o território fronteiriço, inibiu o avanço de exploradores franceses, ingleses e holandeses na área que se estende do Oiapoque ao Rio Cunani.

Em 1900, com a assinatura do Laudo Suíço, que estabeleceu o limite entre Brasil e Guiana Francesa no rio Oiapoque, o Amapá tornou-se oficialmente brasileiro. Contudo, franceses e ingleses continuaram a explorar as terras acima daquele rio. Só então, com o objetivo de conter o avanço francês, o governo federal toma iniciativas que visam ao povoamento da região da fronteira. Em 10 de março de 1920 foi nomeada a comissão colonizadora do Oiapoque, fato largamente registrado pela imprensa nacional conforme é retratado por Alicino (1993, p. 69-90)22:

O Paiz, de 14 de março de 1920, sob o título "Colonização do Amapâ", afirma:

O Amapá é uma terra economicamente roubada ao Brasil.

O ouro, a borracha, as essências florestais e até o gado de sua produção, é objeto de grande e próspero comércio clandestino, promovido por traficantes de além fronteira que, na verdade, gozam a posse mansa e pacífica do ex-contestado.

O Correio da Manhã do Rio de Janeiro de 4 de julho de 1920 ressalta:

É urgente que esses problemas de fronteiras brasileiras não continuem a ser descuidados como têm sido até agora. Bastalhes o flagelo do contrabando, mal irremediável contra o qual as autoridades se confessam impotentes para amparar essas regióes longínquas, livrando-as do aspecto evidente de inferioridade que oferecem diante dos estrangeiros limítrofes.

22 ALICINO, R. Clevelândia do Norte. Rio de janeiro: Biblioteca do Exército Editora, 1971, $136 \mathrm{p}$. 
Augusto Lima, da Academia Brasileira, com um forte protesto publicado na folha $A$ Noite de 6 de novembro de 1920 com o título "só agora..." faz referência ao relatório do engenheiro Ignácio Moerbeck que denunciava a ausência do Brasil naquela parte de seu território, onde só se falava o francês e circulava o franco, com absoluta exclusão de homens e valores brasileiros.

A história do contestado é certamente um retrato do longo período de descaso das autoridades brasileiras que por longo tempo descuidaram de suas "longínquas" áreas limítrofes, relegando-as à própria sorte nas invasóes e exploraçóes levadas a cabo por estrangeiros ao longo de dois séculos. Ela situa naquele território um histórico de convivência de múltiplas nacionalidades, diferentes etnias e culturas diversas que inevitavelmente promoveram o contato de várias línguas. Tal contato se efetivava tanto na concretizaçáo de transaçóes comerciais de ouro, madeira e outros produtos táo comuns nessas paragens, quanto pela necessidade inevitável de integraçáo sociocultural das comunidades que ali habitavam e habitam.

Passados mais de cem anos do plano de povoamento da regiáo do Estado do Amapá e, particularmente, da área que limita o extremo norte do Brasil, a cidade de Oiapoque é semelhante a muitas cidades de fronteira, caracterizada que é pela presença de uma população oriunda de diversas partes do país e pelas comunidades indígenas. Muito embora o Laudo Suíço de 1900 tenha estabelecido alí um limite oficial do Estado-nação, a dinâmica dos povos e das línguas, no entanto, não se extinguiu com ele.

Nos anos 60, com a construção da base espacial francesa, dá-se início a uma intensa movimentação migratória de brasileiros para a Guiana francesa, cujo corredor de passagem obrigatória, sobretudo para imigrantes ilegais vindos de diversas partes do país, é a fronteira Oiapoque e Saint Georges. A valorização da moeda francesa e as recém-criadas, à época, oportunidades de trabalho para os brasileiros na construçáo civil incentivaram muitas famílias a buscarem melhores condiçóes de vida no outro lado do rio, principalmente nos centros urbanos de Caiena e Kourou.

Até o final dos anos 90, essa foi a dinâmica da fronteira: a proporção de brasileiros indo para a Guiana sendo inversamente proporcional àquela dos que vinham ao Amapá, mesmo em caráter de passagem. Com exceçáo das famílias mistas formadas na Guiana, raros eram os guianeneses que atravessavam para conhecer o outro lado. A imagem dos brasileiros em território 
francês estava relacionada, sobretudo, às dificuldades econômicas do Brasil e ao baixo nível de escolaridade dos migrantes que eram percebidos, a exemplo de surinamenses e haitianos, como invasores naquelas terras.

Se a zona de fronteira continuou "pacata" até meados dos anos 90, quando Oiapoque contava uma população de aproximadamente 12.000 (doze mil) habitantes e Saint Georges de cerca de 2.000 (dois mil), época em que praticamente nenhuma ação conjunta oficial era realizada entre as duas comunidades, as ações políticas do final da década vão estabelecer uma nova dinâmica nas relações na fronteira.

$\mathrm{O}$ acordo de cooperação transfronteiriça assinado pelos governos brasileiro e francês, prevendo uma série de açôes conjuntas para a região que incluíam projetos de cooperação sócio-econômica, científica, educativa e cultural foi o pontapé inicial em uma relação que a cada dia se vê mais intensa, porém não menos problemática._

No início do novo século, a chegada da nova moeda europeia na Guiana, aliada aos novos projetos de integração das áreas limítrofes e à abertura da rodovia que liga o Brasil à Guiana Francesa, abriu uma nova perspectiva para as cidades de Oiapoque e Saint Georges. A valorização do euro frente ao real estimulou o turismo de compras na fronteira e se estendeu para a capital do estado; por consequência, o contato entre os povos da região se intensificou e, na mesma proporção, a interação interlinguística.

Com a construção da ponte binacional que promove a interligação entre o Brasil e a Guiana Francesa, finalizada em 2011, uma nova dinâmica nas relaçóes está em jogo; das questóes jurídicas e políticas até as regras de mercado, tudo está em vias de ressignificação e de renegociação. A institucionalização de uma nova ordem para acordos informais estabelecidos ao longo de décadas de convivência não apenas reacende questôes aparentemente superadas, mas desvela os traços de representação da territorialidade que pareciam esquecidos.

\section{$\mathrm{V}$ - Aspectos sociais e linguísticos da fronteira franco-brasileira}

A fronteira franco-brasileira exige uma dupla análise de seus aspectos sociais e linguísticos. É preciso compreender que não se trata de uma única comunidade com duas ou mais línguas, nem mesmo de dois grupos sociais distintos que dividem, sem linha demarcatória, um espaço territorial, mas de 
duas comunidades, cada uma envolvendo uma situação diferenciada de bilinguismo que se vê intensificada pelo convívio de dois povos e pelo respectivo confronto de duas línguas nacionais. De um lado, temos os brasileiros, com suas peculiaridades, seu modo de vida, sua visão de mundo e suas línguas. De outro, os guianenses, que são igualmente franceses (mas cuja identidade étnica não caminha necessariamente de mãos dadas com a identidade linguística) guardando, na mesma proporção da fronteira oposta, características identitárias particulares.

Ao longo de quase um século, as cidades de Oiapoque e Saint Georges estiveram, e ainda continuam, subordinadas política e economicamente às suas condiçôes de periferias nacionais. Saint Georges está para Paris como Oiapoque está para Brasília. Distantes dos centros econômicos e de poder, a realidade tanto social quanto linguística segue ignorada década após década. A situação socioeconômica semelhante e a convivência mútua das comunidades cedo ou tarde instauraria uma realidade multilíngue. Assim, "Se Maomé não vai à montanha, a montanha vai a Maomé" parece ter sido o lema de ambos os grupos para dar início a um frutuoso processo de integração.

O multilinguísmo regional tem função múltipla e contempla diferentes realidades. Nem todos na comunidade brasileira são bilíngues e, quando bilíngues, não o são igualmente, nem no modo de apropriação das línguas, na competência que desenvolveram, nem nas línguas que usam, tampouco nos domínios em que as utilizam. A realidade socioeconômica e o histórico de vida de cada indivíduo são aquilo que compõe o multilinguísmo societal da fronteira.

À exceção da constituição de famílias mistas, o que geralmente leva à apropriação de duas ou mais línguas, é fundamentalmente o trabalho que tem impulsionado o multilinguísmo em Oiapoque. A pressão que sofrem os indivíduos do lado brasileiro para aprender o francês está relacionada às condiçôes econômicas das famílias e à proximidade geográfica com o país vizinho. O baixo nível de escolaridade da populaçáo local, aliado ao inexistente desenvolvimento industrial, ora conduz parte da populaçáo à busca de trabalho no mercado de serviços e no comércio logístico, ora leva os indivíduos a lançarem-se no mercado informal. Qualquer uma das situaçôes, envolvidas que estão no contexto de atendimento ao público que vem do outro lado da fronteira, impulsiona a necessidade de aquisição e de uso da nova língua. 
Em Saint Georges, o multilinguísmo está fundamentalmente ligado à realidade social diglóssica. Diferente de Oiapoque, onde o bilinguismo ocorre preferencialmente na idade adulta, ali a maioria dos habitantes é bilíngue desde a infância. O português, que se soma às duas línguas da comunidade, não tem seu aprendizado relacionado com a necessidade econômica das famílias, mas, sobretudo, com a realidade social e geográfica. Saint Georges tampouco tem indústrias ou um comércio local forte, porém, a maioria da comunidade é formada por funcionários públicos cuja renda é três vezes maior que a renda dos brasileiros. Falar português para eles tem como objetivo maior estabelecer uma convivência social pacífica com a comunidade vizinha ou exercer as funções repressivas como ocorre com a polícia de fronteira.

Por outro lado, o status de uma língua em uma dada comunidade linguística em relação às outras com as quais está em contato é condicionado por vários fatores que se estendem desde o poder econômico até o uso efetivo da língua pelos falantes.

O poder linguístico de cada língua, o valor econômico e a função social das línguas são diferentes de um lugar para outro. Tanto em termos de legalidade quanto de poder e valor econômico, o português e o francês, de um lado, e o crioulo e o patuá, de outro, estão caracterizadamente dividindo de forma desigual o espaço fronteiriço.

$\mathrm{O}$ uso institucionalizado juridicamente ou não do francês e do português nas comunidades é altamente superior àquele registrado pelas línguas minoritárias. A separação que diferencia o status e o prestígio de uma língua para outra é clara: enquanto o francês é a língua prioritária do comércio, do trabalho informal, o crioulo e o patuá são usados e percebidos como línguas da minoria, de grupos étnicos. O português, em contrapartida, é a língua das relações interpessoais. É a língua do "entre amigos". O português é percebido como a língua de contato entre diferentes. Daí ela figurar como uma das línguas de maior prestígio entre as línguas estrangeiras aprendidas na fronteira francófona.

Em termos demográficos, o português é a língua da maioria. Para cada francófono há na fronteira cinco luso falantes, muitos deles vivendo dentro do espaço francês e ali também usando a língua portuguesa. Essas proporçôes ficam ainda maiores se comparadas ao crioulo e ao patuá; porém, o fator demográfico não basta para determinar o status de uma língua, ele é só um dos elementos, podendo ser atenuado por outros fatores. 
Um destes fatores é o poder econômico que se manifesta na importância dos povos que utilizam uma determinada língua, e também nas suas riquezas e na produção econômica e cultural. Na fronteira franco-brasileira, o francês é a língua que ocupa maior importância econômica no mercado. É claramente uma relação comercial estabelecida entre o mais forte e o mais fraco, economicamente falando, estabelecendo também uma relação de oferta e procura que conduz as relaçóes de força entre as línguas da região. Dessa forma, a língua de prestígio do comércio local é o francês, que se torna, por conseguinte, um pré-requisito no mercado de trabalho.

Contraditoriamente, o ensino da língua na fronteira brasileira não parece fazer jus à necessidade da população em aprender o francês nem ao poder econômico que a língua representa na regiáo, o que nos força a estabelecer uma relação muito mais ampla, resgatando aqui o valor da língua de maior prestígio econômico em nossos dias, não só no Brasil, mas no mundo: aquele da língua inglesa. De ambos os lados da fronteira, o inglês é a língua estrangeira mais estudada pelos habitantes da regiâo, seja por escolha própria, como é o caso de Saint Georges, seja por imposição, como acontecia, até 2005, em Oiapoque. Esses elementos denotam a ausência de açóes político-linguísticas concretas e apropriadas para o lado brasileiro da fronteira.

A prática do monolinguismo instituída no Brasil e na França, baseada no princípio da nacionalidade, desconsidera o fator fronteiriço, sobretudo no que diz respeito ao ensino de línguas estrangeiras e /ou segundas línguas. Longe de ser só mais uma disciplina da grade curricular, o francês em Oiapoque e o português em Saint Georges são línguas em uso no grupo social que compóem brasileiros e franceses.

A escola, vale lembrar, é um dos mais potentes meios de intervenção na gestão das situaçôes linguísticas, guardando uma parte importante na avaliação do status de uma língua na comunidade. Mais do que em lugares onde o contato com estrangeiros é esporádico, a possibilidade de acesso ao aprendizado de uma língua estrangeira que está presente no dia a dia das pessoas é não só uma necessidade socialmente comprovada, em contraponto com o aprendizado que representa antes de tudo status social, mas, sobretudo, um direito e uma oportunidade aberta para o desenvolvimento das comunidades de fronteira.

A ausência de açóes pontuais relativas ao ensino de línguas em Oiapoque vem mostrar em primeiro plano não somente a ausência de uma política 
linguística diferenciada e necessária para aquele espaço particular, mas também um forte desconhecimento do composto social, econômico e linguístico da fronteira franco-brasileira.

\section{VI - Considerações finais}

Não é preciso ir muito além de uma busca detalhada na internet e nos sites de pesquisas linguísticas para descobrir que só muito recentemente os estudos do contato têm ocupado espaço nos estudos linguísticos brasileiros. E, nesse conjunto marcado majoritariamente pelo contato de brasileiros com hispano-falantes, a fronteira francófona é quase desconhecida, porém, independente de ser conhecida ou não, a fronteira franco-brasileira vive suas próprias realidades e seguem sendo, em certa medida, uma tradução do conjunto de regras que delimitam a paisagem política, jurídica, social, econômica, cultural e linguística deste estado-nação plurilíngue e pluricultural que é o Brasil.

Para além do fator linguístico, as fronteiras existem também enquanto fronteiras étnicas e culturais no seio de fronteiras nacionais. Retomando as palavras de Moreau (2004, p. 125-134) ${ }^{23}$ :

"as fronteiras marcam - em função das diversas experiências e objetivos - o limite entre o "aqui" e o "ali", entre o "deste lado" e o "lado de lă"; entre o "familiar" e o "estrangeiro"; entre o que "me pertence" e o que "te pertence"; as fronteiras separam os "in-groups" dos "out-groups"; elas são sinônimos de proteção contra o exterior; elas demarcam o indivíduo, traçam uma linha de pontos comuns, de contato com o Outro e evocam a possibilidade de um comum".

Nesse contexto de comunicação exolinguística constante, toda ação entre os homens necessita do veículo da língua para se estabelecer. As línguas representam possibilidades de expressão culturalmente marcadas. Elas são, podem e devem ser parte integrante de uma "política de fronteira" que pode

23 Moreau, M-L. «Langues de frontières et frontières de langues «. Glottopol, Revue de Sociolinguistique en ligne, 4: 125-134, Rouen, 2004. 
tanto se tornar instrumento de demarcação territorial, cultural e das individualidades quanto se tornar uma oportunidade de encontro, de contato e de cooperação entre dois povos.

A proximidade entre comunidades e a necessidade de integração em maior ou menor escala entre as pessoas permitem um maior conhecimento daquilo que o país fronteiriço tem a oferecer cultural e economicamente. Os indivíduos que vivem a realidade fronteiriça estão compelidos ao mesmo tempo a dar respostas às suas próprias necessidades pessoais e específicas e a contribuir com o desenvolvimento dessas regióes periféricas do país, aproveitando a proximidade do vizinho para combinar recursos intelectuais e materiais. É essa condição que faz com que o aprendizado das línguas em presença se torne uma necessidade evidente.

As possibilidades de aprendizagem no meio social são significativas em função, por exemplo, dos meios de comunicação (rádios locais), dos contatos pessoais, dos cartazes publicitários expostos nas ruas, dos slogans, dos nomes adotados no comércio local etc.; porém, isso só não basta. As fronteiras precisam de políticas linguísticas (sociais e econômicas) que considerem as necessidades individuais e sociais, que explorem os recursos comuns e que combinem as duas perspectivas: a social e a individual.

Nestas regióes é necessário ter conhecimento das línguas que possibilitam às pessoas contribuir tanto para o progresso social quanto para a conformação das identidades grupais. Cabe-nos, portanto, suscitar aqui os resultados da ausência de uma política linguística adequada às realidades fronteiriças.

O favorecimento do ensino da língua inglesa e espanhola em detrimento da língua francesa - refletindo a realidade nacional e não local - impóe à comunidade brasileira mais uma situação de desvantagem frente à realidade vizinha. O ensino do inglês em Oiapoque, embora não convenha dispensá-lo, uma vez que se insere em um contexto mais global, mostra-se inexpressivo para pessoas que raramente saem dali ou raramente entram em contato com falantes daquela língua. Faz-se necessário, portanto, desvendar a consciência de que não somos o país monolíngue que muitos imaginam, que os contatos de fronteira não são exclusivamente com hispano-falantes e, sobretudo, que um país multilíngue e multicultural é antes de tudo múltiplo de realidades que demandam açóes condizentes com seus diferentes contextos sociais, políticos, econômicos e linguísticos. 


\section{FRONTIÈRES LINGUÍSTIQUES ET FRONTIÈRES POLITIQUES: RELATIONS LINGUISTIQUES ET SOCIO- HISTORIQUES À LA FRONTIÈRE BRÉSIL/GUYANE FRANÇAISE.}

RÉSUMÉ:

Cet article soulève la réalité de la frontière franco-brésilienne, embriquée de ses aspects historiques et sociaux, et l'étude du contact. Ayant comme postulat le concept de contact et des phénoménes que lui sont inhérents on élabore un portrait historique, socioculturel et linguistique de la frontière Brésil - Guyane Française et des résultats de ce contact dans la vie quotidienne des habitants de la frontière. Pour conclure on relève des questions relatives aux politiques linguistiques éducatives.

MOTS-CLÉS: Frontières politiques; contact linguistique; usages sociaux.

Recebido em: 11/02/2013

Aprovado em: 12/08/2013 